\title{
The Impact of Hand Washing Initiative on Young People in the Eastern Region of Ghana
}

\author{
Gertrude Narkie Tetteh $^{1 *} \quad$ Gina Teddy ${ }^{1} \quad$ Erasmus Tetteh-Bator ${ }^{2}$ \\ 1.Graduate School of Public Service and Governance, Ghana Institute of Management and Public Administration \\ (GIMPA), Accra, Ghana \\ 2.Department of Mathematics and Statistics, University of South Florida, 4202 E Fowler Ave, Tampa, FL, USA. \\ * E-mail of the corresponding author: nanagertytetteh@yahoo.com
}

\begin{abstract}
Hand washing has been a lifelong practice because of its many health benefits, social and moral obligations. It is perceived to be one of the most important and cost-effective methods of preventing infectious and diarrhoeal diseases like the Coronavirus disease 2019, (COVID-19). (Ghana Health Survey, 2020). Promoting hand washing as an intervention for hand hygiene and behaviour change activity for continuous practice have been rolled out among young people so that they learn proper hand washing and maintain personal hygiene. This study assesses the impact of hand washing initiative among young people in the Eastern Region of Ghana.This is an exploratory and qualitative study that combines a Focus Group Discussions (FGD) of young people and InDepth Interviews of key stakeholders such as parents, teachers, community leaders, health workers and NGO's in the Eastern Region of Ghana. The data derived from the study was analyse using a qualitative technique such as thematic analysis to extract the key findings. During the study, ethical considerations were observed to protect respondents.Key findings from the study indicates that there is a general awareness of hand washing and its importance among young people. However, they find it difficult to adhere to the practice because of nonavailability of basic items such as soap, water and knowledge of proper hand washing techniques. The study also revealed that key stakeholders contribute to promote hand washing initiative in diverse ways at home, in schools, health facilities and in the community. However, some stakeholders are predisposed to resources that enable them to achieve hand washing initiative. The least of those not predisposed to basic resources to support the practice are teachers, schools and community leaders because of shortage basic resources such as soap and water to support the practice of hand washing. This study concludes that despite all the efforts by young people to adhere to practice and key stakeholders' effort to promote hand washing, they are confronted with basic challenges. Hence, the need to have basic resources such as water and soap in schools and communal areas, to advocate for young people to engage in global hand washing day and using young people as ambassadors to advocate for proper hand washing practices especially among their peers.
\end{abstract}

Keywords: Infectious Diseases, Hand Washing Initiative, Non-Governmental organizations, Focus Group Discussion, Thematic Analysis, Behavioural Changes

DOI: $10.7176 / \mathrm{PPAR} / 11-4-01$

Publication date:May $31^{\text {st }} 2021$

\section{Introduction}

Hand washing is the single most important method of preventing infectious disease such as diarrhoea among children and young people. Hands can be contaminated with faces, fluids, dust, germs and viruses which can be transferred to things we handle such as chairs, door knob, handles, tape holders, electronic devices, keys and the floor (CDC), 2011). Furthermore, infectious disease-causing agents can enter the body when the unwashed hands touch the nose, month, eye, ears, etc. When a person with respiratory infection sneezes or coughs, the droplets that remains in his/her hands or the object used can contaminate another person upon contact. When that person touches another's hands and that person touches his or her month, eyes, ears and nose without washing their hands, the person can be infected with respiratory infections such as influenza, common cold or other related infectious diseases (Rabie et al., 2006) such as the Nova Corona Virus that is currently circulating. This underscores the fact that hand washing will not only promote hand hygiene, it will also prevent several other infectious diseases and acute respiratory infections.

The significance of hand washing was first discovered by Holmes in 1843, working in an obstetric yard where about $25 \%$ of women delivering were dying from childbed fever (Puerpenepsis). Investigations by Holmes found that it was transmitted through contaminated hands of doctors when delivering mothers. However, the idea was turned down by media specialists (Gallup and Sachs, 2009). In 1847, Semmelweis proved that hand washing was effective in the prevention of infections and demonstrated that childbed fever incidence could be reduced from $2 \%-3 \%$ or less when appropriate hand washing practices are done by medical workers. However, the idea was also mocked by health practitioners (Lerman, 2008). Despite the rocky beginning of the significance of handwashing, it has become one of the most important aspects in the protection against the spread of infections worldwide. 
Young people are known to be highly susceptible to diseases such as diarrheal and respiratory infections (Berg, 1988). Studies have recommended hand washing as the best means of preventing diarrheal diseases transmission, despite not being the sole route of transmission.

In recent years, hand washing with soap and other forms of hand hygiene has been gaining recognition as a cost effective, essential tool for achieving good health and personal hygiene among young people. The simple act of hand washing with soap has the potential to save millions of lives, yet hand washing remains one of the most commonly neglected life-saving practices. Worldwide, the observation rate of hand washing with soap at critical moments particularly after using the toilet has fallen from 0 to $34 \%$. In Ghana one child out of every twelve born alive dies before the age of five and diarrhoea accounts for a good number of these childhood deaths. One thousand four hundred children under the age of five still die every day from infectious and diarrhoeal disease caused by lack of safe water, sanitation and poor hygiene (UNICEF, 2014).

\subsection{Conceptualising Hand Washing}

The concept of hand washing is very critical and relevant in Ghana because of the dust prone environment and the outdoor living typical of tropical regions as well as the kind of dishes Ghanaians love to prepare, eat or buy. In Ghana, the issue of hand washing is even much critical because most of us like eating with our hands. Traditional foods such as fufu, kenkey, banku are preferred eaten with the bare hands rather than with cutlery. Most cereal and grainy foods such as rice, waakye and others are also culturally eaten and enjoyed with hands and not with the aid of cutlery. These cultural eating practices make it very important for people to practice hand hygiene.

Hands are the main pathways to germ transmission during ill health. Hand hygiene is therefore one of the most important measure to avoid the transmission of harmful germs and prevent health care-associated infections. The main medical purpose of washing hands is to cleanse the hands of pathogens such as bacteria, viruses, or other microorganisms that can cause disease as well as chemicals which can cause harm or diseases. (WHO, 2009).

Hand washing, also known as hand hygiene is the act of cleaning hands for the purposes of removing soil, dirt and microorganism. The act involves rubbing your hands with soap and water, or other detergents containing an antiseptic agent (WHO, 2009; Melinda, 2002).

Following the recent nova corona virus pandemic, the WHO recommended frequent hand washing with soap under running water by all to avoid infections, contamination and cross contamination.

The correct steps by the CDC on how to wash your hands with soap and water includes:

1. Wet your hands with cleaning running water (warm or hot as tolerated), turn off the tap, and apply soap.

2. 2. Lather your hands by rubbing them together with the soap. Be sure to lather the back of your hands, between your fingers, and under your nails.

3. Scrub your hands for at least 20 seconds. Hum the "Happy Birthday" song from beginning to end twice.

4. Rinse your hand well under clean, running water.

5. Dry your hands using a clean towel or air dry them.

6. Use your paper towel to turn off the water after you are finished.

Washing hands with soap and water is the best way to get rid of germs in most situations. In the absence of soap and water, one can use a hand sanitizer to clean their hands. You can use an alcohol-based hand sanitizer that contains at least $60 \%$ alcohol. Swallowing alcohol-based hand sanitizers can cause alcohol poisoning if more than a couple of mouthfuls are swallowed. (CDC, 2015). It is worth noting that sanitizers do not get rid of all types of germs and also might not remove harmful chemicals from hands like pesticides and heavy metals. (CDC, 2015).

The correct steps by the $\mathrm{CDC}$ on how to washing your hands using a hand sanitizer

1. Apply the gel or alcohol-based product to the palm of one hand. It is worth reading the label to learn the correct amount required and usage instructions.

2. Rub the sanitizer in your hands together.

3. Rub the sanitizer over all the surfaces of your hands and fingers until your hands are dry. This should take around 20 seconds.

Hand washing with soap is the single most effective and inexpensive way to prevent diarrhoea and acute respiratory infections (ARI) and a common behavior performed in homes, schools, and communities worldwide. (UNICEF, 2014). This is especially important for people who handle food or work in the medical field, but also an important practice for the general public (Melinda, 2002). Hand Washing with soap impacts not just health, sanitation and nutrition, but also education, economics, and equitable access to health and sanitation resources (Global Hand Washing Partnership, 2017).

\subsection{Availability, Adequacy and Accessibility of Hand Washing Supplies}

The term "Hand Washing Facility", as defined by Heenan, as "a facility, providing a basin, container, or outlet 
with adequate supply of portable running water, soap and single-use towels (Heenan, 1992). A hand washing facility, even with soap, on a communal basis, where more than one person uses the same water, does not constitute an adequate hand washing facility (CDC, 2007). Studies in developing countries consistent with the present study have shown that lack of soap is one of the barriers to hand washing in schools; since most of these schools have neither soap nor appropriate hand washing facilities (Bolt et al., 2006).

Lack of resources, namely soap and water, as well as inadequate sanitation facilities may be two of the main reasons why young people do not wash their hands. The report of the 1998 Mayo Foundation for Medical Education and Research (MFMER) has proved that the proper use of an alcohol-based hand sanitizers-which do not require water-are an excellent alternative to hand washing, particularly when soap and water are not available (MFMER, 2009).

In addition, Cairncross (1997) emphasized that water availability is likely to have an impact on frequent of hand washing. When water is farther than about a kilometre from the home, mothers turn to restrict their use of water for hand washing. On the other hand, when water is freely available at close range, hand washing becomes more frequent. However, hand washing behavior is affected by lack of hand washing facilities (supplies) like the number of water points for hand washing, access to water point, availability of water and soap. (Morgan et al., 2017).

Many schools in developing countries rarely make available adequate hand washing facilities and those schools that do provide such facilities have issues the adequacy of those facilities, proper places to site them and sometimes not very much accessible by the people (Morgan et al., 2017). Having regular supply of clean water for washing hands with soap only can greatly help in increasing the rate at which individual practice hand washing. Also, the availability of clean running water and soap for hand washing can help to reduce infections by almost $30 \%$. (CDC, 2017).

\subsection{Sustainability of Hand Washing Practices}

Improving hand washing practice and sustaining hand washing practice suggests determinants such as social norms, policy and programs, and the presence of "enabling technologies "(like tippy taps and water treatment products).

Initiatives such as the Global Hand Washing Day that focuses on the use of soap to wash hands to prevent diarrhoea, acute respiratory infections and other germ related diseases are marked in Ghana once every year as much as other countries. Global Hand Washing Day was founded by the Global Hand Washing Partnership, and is an opportunity to design, test, and replicate creative ways to encourage people to wash their hands with soap at critical times. Global Hand Washing Day is celebrated every year on October 15th. The aim of the Day Celebration is to sensitize and engage the youth and schools in acknowledging and promoting the essence of handwashing. The youth act as agents of change and take the good practice of hygiene learned at school back into their homes and communities.

The active participation and the involvement of the youth, along culturally sensitive community-based interventions which have been the motivation force is aimed at ensuring sustained behavioural change, while hand washing with soap particularly at critical moments including after using the toilet and before handling food, has been proven to be a key cost effective and lifesaving interventions (Smith-Asante, 2012). This is because when hand washing is practiced regularly, it will foster social inclusion and individual self-respect by offering an alternative to stigma and marginalization. This study therefore explores the practice and its impact on the youth in the Eastern Region of Ghana through the following; assessing the level of awareness of young people on the hand washing. Determining the benefits and significance of hand washing with soap among young people. Analysing the roles of key stakeholders in supporting hand washing with soap in the communities and at schools. Identifying challenges associated with implementing hand washing initiative.

\section{Material and Methods}

\subsection{Data Collection Technique}

The study was conducted in the Fanteakwa District located within the central part of the Eastern Region of Ghana.

With the introduction of the WASH programme by both UNICEF in 2015(UNICEF Annual Report, 2015) and World Vision (News Ghana.com, 2016), young people in the district have benefited from personal hygiene and hand washing sensitisations including the Ebola and Cholera programme in 2016 where twenty two (22) senior high schools in the district benefited from hand washing education and donations of handwashing facilities. Also, capacity of stakeholders such as SHEP coordinators, health workers, community leaders were built to support young people in all these programmes (Christian Council of Ghana Annual Report, 2017). Hence the study in the Fanteakwa district among young people as well as stakeholders in hand hygiene promotion among young people.

Purposive sampling technique was used in the study. The objective was to identify particular or unique 
types of cases for in-depth investigations. The study participants were therefore selected through purposive sampling because of their position and relevance to the study in hand hygiene, education and sensitisation programmes as well as hand washing educative programmes. By this approach the study was able to target people who possess some vital information required for the study. Hence, all respondents were selected based on their technical qualities and knowledge needed as well as their contributions to educative programme on handwashing among young people.

The population for the study were young people, health workers, teachers and community leaders within the Fanteakwa District. Also, the snowball technique was used in the sampling process to locate young people and stakeholders who had taken part in hand hygiene program in the district. The In-depth interview was conducted with 20 stakeholders (Teachers, Health workers and Community leaders) and a Focus group discussion was conducted with young people from the senior high schools in the district.

The research was a case study and exploratory in nature, hence a qualitative method which is most suitable for the exploratory and case study design was used. Qualitative study is the most appropriate technique formulating, for investigating the issues, producing data and information in the field. The study employed Focus Group Discussion (FGD) and the In-Depth Interview (IDI) in collecting the data.

\subsubsection{Focus Group Discussion (FGD)}

To seek a collective understanding, perception and experience of young people of the issues of handwashing practices, we used the Focus Group Discussion (FGD). FGD is a qualitative research method and data collection technique. It's essentially a "series of discussions to obtain perceptions on a defined area of interest" (Krueger and Casey, 2009: 2). Typically, this enable us to gather adequate information from the participants through discussions and probing of issues of interest. The process of informal discussions occurs in a group of no more than 12 individuals, with the young people who share some common characteristics (Franz, 2011) such as living in the same community and mostly of school going age. Young people here "have a direct experience of the topic", and, thus, are treated as key to the topic. These discussions are facilitated by a moderator, who introduces topics for discussion and helps the group to participate in a lively and natural discussion amongst themselves. (Asbury, 1995; Smithson, 2008).

The group's composition and the group discussion were carefully planned to create a non-intimidating environment, so that participants felt free to talk openly and give honest opinions. The course of the discussion was usually planned in advance and the moderator used a question guide as an outline to ensure that all topics of interest are covered (Acocella, 2012: 1127). FGD can be useful in providing an insight into different opinions among different parties involved in the change process, thus enabling the process to be managed more smoothly.

\subsubsection{In-Depth Interview (IDI)}

The in-depth interview is another qualitative research method that enable us conducts intensive individual interviews with a small number of respondents to explore their perspectives on a particular idea, program or situation, etc. We therefore engaged key stakeholders in the implementation of hand washing practices of young people in the Fanteakwa District of the Eastern Region of Ghana. This include teachers, community leaders, NGOs and parents.

In-depth interviews are useful when you want detailed information about a person's thoughts and behaviors or want to explore new issues in depth. The aim is to get different perspectives on the same topic and compare experiences on that particular subject/problem. Interviews are often used to provide context to other data (such as outcome data), offering a more complete picture of what happened in the program and why. It offers the opportunity to capture rich, descriptive data about how people think and behave, and unfolding complex processes (Carolyn Boyce and Palena Neale, 2006). It is for these evidential reasons that we adopted the interview process to enable achieve the depth in perceptions and experience sharing on the subject of hand washing by key stakeholders.

\subsection{Data Collection Process and Respondents}

Three field assistants helped in the data collection process. Respondents that engaged in the in-depth interviews are teachers from: Adjeikrom Senior High School, Presby Vocational School and Begoro Senior High School, health workers from Ahomahomaso CHIP Zone, Salvation Army Health Clinic, Begoro Hospital and community leaders from Ahomamu, Besibuom and Asiato. The FGD was conducted in schools with young people at Begoro Senior High school, Adjeikrom Senior High School, among others and out of school young people from Ahomahomaso, Besibuom and Asiato.

Each interview lasted for about 30 to 40 minutes with the interviewer using a question guide to support the process and probing when interesting issues are raised. We conducted two FGD sessions that lasted for an hour each. With the IDI and FGD, the interviewers and moderators did self-introduction, shown appreciation to participants for acceptance of participation and followed the ethical procedures outlined for the study before undertaking the data collection. The objectives of the study were read and explained to respondents to seek their consent. They were assured of their safety, anonymity and confidentiality as it was key to support respondents 
and make them emphasise a choice as well in engaging or not in the research. Questions were then asked according to the interview and FGD guidelines and recordings were done manually while notes were also taken when necessary.

\subsection{Thematic Data Analysis}

Thematic analysis is a good approach to qualitative research where you're trying to find out something about people's views, opinions, knowledge, experiences or values from a set of qualitative data. For example, interview transcripts, focus groups, social media profiles, or survey responses (Braun \& Clarke, 2013). For this study, the types of qualitative data collected makes the thematic analysis appropriate as it allow compare opinions, knowledge and experiences while making sense of the rich set of data gathered from respondents.

The data collected was analysed thematically using inductive approach of generate patterns from the data sets. An inductive approach was most appropriate as it allowed us to use the data to determine the themes and then compared them to existing knowledge. This thematic analysis enabled the qualitative data to extract and apply themes emerging from the interview transcripts.

The research closely examined the data to identify common themes - topics, ideas and patterns of meaning that come up repeatedly. There were emerging themes that we focused on to examine the themes or patterns to make meaning of the data. This method emphasized both organization and rich description of the data set and theoretically informed interpretation of meaning. It means pinpointing, examining, and recording patterns (themes) within data. Themes are patterns across data sets that are important to the description of a phenomenon and are associated to a specific research question. The themes become the categories for analysis.

\subsubsection{Process of Thematic Data Analysis}

Adopting Braun and Clarke (2013) approach, we adapted the steps of creating meaningful patterns for data analysis. These phases are: familiarization with data, generating initial codes, searching for themes among codes, reviewing themes, defining and naming themes, and producing the final report.

The interview recordings were first and foremost transcribed into transcripts to enable the analysis of the data. These transcripts have stories to tell from each respondent which can be achieved by determining the similarities and differences in the stories told. So, we read the transcripts several times while engaging other materials and notes taken during the research to code key points emerging from each transcript. This enabled generate an initial list of items from the data set and note reoccurring patterns across the data. This provided a systematic way of organizing and gaining meaning for the coding process.

Some of the initial codes formed the themes and where a theme becomes too big, we generated sub-coding or subthemes to address the issues emerging from the data. We identified the relationships between codes and themes and between different levels of existing themes. Themes differ from codes in that themes are phrases or sentences that identifies what the data means. They describe an outcome of coding for analytic reflection. Themes consist of ideas and descriptions within a culture that can be used to explain causal events, statements, and morals derived from the participants' stories (Braun \& Clarke, 2013).

A set of themes were generated and later expanded or merged depending on what was more appropriate during the writing up of the findings. These allowed for analytical views and possible new patterns and issues in the data to be analysed. Each of these themes was further analysed to work out the scope, focus and determining the 'story' they are telling in relation to the specific theme. The researchers wrote the final report making meaning of the key points or themes emerging from the data and useful contributions to answering the research questions. These themes became the topic and sub-topics reported in the findings sections as the report.

\section{Results and Discussion}

Key themes that emerged and guided the findings are: awareness of hand washing practices, sources of awareness, knowledge and awareness of the global hand washing day (GHWD), perception of proper hand washing practices, perceptions on when to practice hand washing, availability of hand washing facilities and their impact on the practice, promoting hand washing and the role of stakeholder, benefits of hand washing practices, challenges associated with hand washing practices.

\subsection{Level of Awareness and Sources of Awareness}

Respondents show different level of awareness by giving different definition of hand washing and what it involves. Findings revealed that most of the respondents were aware and well sensitized of hand washing. It was also noted that, majority of the students had deeper knowledge of hand washing and its associated benefits in promoting good health hygiene. Most participants also demonstrated knowledge of the difference between proper hand washing and normal hand washing to be the presence and use of soap. However, they all noted that water is important for the process of hand washing irrespective of its effectiveness.

Despite these responses, most respondents failed to acknowledge hand washing process must be done under running water. It was identified that, respondent became aware of hand washing through parents, teachers, health 
workers, NGO's, friends and the media (Radio, Television and the print).

\subsection{Level of Awareness of young people on the Global Hand Washing Day}

It was revealed that, respondents' level of awareness about the Global Hand Washing Day was low. The few of the respondents aware of the Global Hand Washing Day were able to explain what the day is about. Health workers and teachers are the most familiar as compared to community leaders and members. In relation to the month and day dedicated for the celebration, most of the respondents could not tell the date of the celebration. Also, it was revealed that young people acknowledged the importance of the Global Hand Washing Day after it was explained to them and where able to narrate how this day is celebrated across different schools, hospitals and community centres. The few respondents who had participated in the celebration of the day shared the celebration was a good platform for sensitisation on hand washing as well as opened an opportunity to observe and participate in practical hand washing processes.

Creating awareness during the WHWD is a major activity identified by most respondents who have experience the day. Respondents in the FGDs explained that teachers, NGOS, health workers, UNICEF and other promulgators of the WHWD have engage with them in schools, hospitals and sometimes at the communities educating on proper hand washing practices to celebrate the day. It was also reported that most of the activities are interactive which helps participants in the activity to remembers the practice. Health workers also reported that they go on outreaches at schools, churches, communities' centres, lorry parks and market places to educate people on the day mostly using durbars, demonstrations and talks. Others also indicated that they spend the day educating people who visit the health facilities on hand washing, whereas Communities leaders use the media such as local radio and TV stations. most respondents believe continuous celebration will enhance that awareness creation and promote the practice.

\subsection{Hand Washing Practices}

The study showed that, most respondents wash their hands with soap and water after visiting the toilet or before eating whereas, few uses hand sanitizer. It was also found that washing hands with soap and water was the best way of keepings the hands clean. However, there was no consensus as to which of the items is applied first and which part of the hand is to be washed first. The most common practice of hand washing described by respondents is that one must use soap first before applying running water and robing the palms, the back of the hands, with most people including the fingers, finger tips and the arm. It was noted that, most young people do not practice hand washing as a result of unavailability of hand washing facilities (water, soaps etc) but rather respond to the feeling of dirt or filth.

Most respondents identified that the practice is useful for hygiene purposes before and after eating, after using the toilet, when they soil their hands or feel it is contaminated with a chemical, dirt, filth, etc. The perception of dirt, filth and contamination is the strongest drive for people engaging in the practice. People mostly do not practice hand washing more than three times a day and mostly practice hand washing only after using the toilet. This is consistent with the study of the Ghana Health Survey (2016) where people will not wash their hand as a reform activity but to respond to dirt and filth as the need be.

It is also evident from the views above that adults wash their hands more frequently and have a better sense of personal hygiene informing their adherence to the practice than young people. Even though younger people equally know the benefits of hand washing. They demonstrated that adults make conscious efforts mostly to wash their hands than young people because of their roles and positions as parents, health workers, teachers or leaders in the home or communities. Respondents also showed that washing one's hands frequently becomes a habit, specifically, before and after eating. It becomes so routine that one does it without thinking or questioning its essence and it becomes easier to practice it.

\subsection{Hand Washing Facilities at Homes, Schools and Health Centres:}

Hand washing facilities are important and very impactful on achieving the process or not. The study noted that facilities for hand washing were present but incomplete, with the absence of one or two items needed for the proper hand washing process to take place. Among those mostly mentioned were tapes without flowing water, veronica buckets without water and the presence of water without soap or hand dryer. Also mentioned are sanitizer dispensers without hand sanitizers. However, hand washing is mostly done frequently by young people when facilities are available. It was revealed that most homes with toilet facilities do not have set ups facilities for hand washing, that makes it difficult for young people to practice hand washing frequently. This confirms a study conducted by Lopez-Quintero et al in 2009.

The study asserted that several developing countries consistently reported lack of soap and unavailability of water. The study recognised the lack of resources, namely soap and water, as well as inadequate sanitation facilities may be two of the main reasons why young people do not wash their hands and that young people do not practice hand washing as a result of unavailability of hand washing facilities (water, soaps etc). The 
responses show that different people are responsible for the provision of these facilities as schools, parents, health facilities, community leaders, NGOs and institutions within the region are responsible for providing these facilities. Also, there is complementary effort required for the provisions where parents must do their bit while teachers, health workers and NGOs complement those efforts.

\subsection{Stakeholder's Role in Promoting Hand Washing:}

With regard to whose responsibility it is to support young people to practice hand washing, almost all respondent said parents, teachers, health workers, NGO's, friends and the media (Radio, Television and the print) have the responsibility to teach young people hand washing as well as draw their attention consistently. Also, the study revealed that, the connection of the role played by these stakeholders as to where one's role begins is the commencement of another person's role and the support of each other in the process. NGO's stood out as the main stakeholder actively performing it role in hand washing among young people.

Staff of the sampled NGOs also revealed that they visit most schools, churches and communities within the district for awareness creation, and education on the processes on proper hand washing. They also donate items such as soaps, veronica buckets, bowls, barrels, tanks and hand sanitizer dispensers to most schools and health facilities.

Health workers noted that they use the community information centre and the radio station to share information on hand washing and its related benefits. They educate patients at the facilities using poster and educational material. Parents also indicated they teach their children how to wash their hands anytime they use the toilet or before meals. The least players mentioned were teachers and the reasons identified was the unavailability of resources to perform their role.

\subsection{Benefits and Significance of the Hand Washing Initiatives}

The results showed how people of Fanteakwa have benefited from the hand washing initiatives. It was found that prior to the hand washing initiative, people in the district frequently experience common illness like cold, flu, typhoid and other infectious diseases. It was revealed that the initiative has helped minimized the rate at which people get typhoid, fever and infections in the district. It was also noted from a health worker that, the rate at which clinics and hospitals record cases of infections, typhoid and other health related diseases of not practicing hand washing has been reduced drastically. In spite of young people not performing hand washing consistently and correctly, they could mention the benefits of the practice mostly in relation to health and personal hygiene.

The study revealed, washing of hands before and after eating had become in a way, a formality for most young people. From the above responses, it is evident that the benefits of hand washing practices are not simply health related or the prevention of illness but inculcate good health that builds healthy habits with social and economic implications. Therefore, hand washing has not only help to promote hygienic practices, it has shaped social practices of the people by inculcating this into their lifestyle for eating, sharing food, running their homes and communities. Also, the healthier the residents and population in the regions, the more engaged they are in productive activities with implications for improved economy.

\subsection{Challenges associated with the Hand Washing Initiatives}

The study revealed that hand washing practices were reported to be highly challenged with adverse implications. Some of the factors identified are: lack of hand washing facilities; weak behavioral changes, lack of funding to support; poor practices at home, and inconsistent educational programs.

The study found out that the unavailability of items for hand washing such as water and soap specifically in schools and health facilities possess a great challenge to young people practicing hand washing. In most cases, the absence of one item such as availability of water or soap affects the effectiveness of the practice. having hand washing basins and sink without flowing water. Resources such as veronica bucket, bowls, soaps, water tanks, etc. specifically in schools and health facilities were mostly lacking impeding the efforts to promote the practice.

The non-availability of facilities and finance also affects the celebration of the Global hand washing day in schools and health facilities. This has implications for sustainability of practice and continuity especially for young people learning the practice of hand washing.

Another challenge worthy to mention is related to the correct way of washing hands. Changing behaviors of young people in relation to hand washing practices in one's everyday life is a concern. For instance, most people indicated they do not wash their hands under flowing water, wash in between their fingers and clean their nails. In schools they tend to wash their hands in a bowl of water, using the same bowl of water for everyone. This can cause contamination of the hands.

The study again found out that the inadequate media support to promote hand washing particularly for the youth had been identified as challenge to the practice among young people. 


\section{Conclusion}

Hand washing is the most important and cost-effective methods of prevention of infectious diseases such as diarrhoea which young people are most at risk of. Global Hand Washing Initiative is dedicated to increase awareness and understanding about the importance of handwashing with soap as an effective and affordable way to prevent diseases and save lives.

The study found out that there is high level of hand washing awareness among young people with deeper understanding of normal and proper hand washing and its associated benefits in promoting good health. The level of awareness of the hand washing day is low among the youth. The month and the day set for the Global Hand Washing Day is not known by majority of young people interviewed, however, they were aware of what the day is about.

It was revealed that most young people wash their hands with soap and water after visiting the toilet or before eating whereas, few uses hand sanitizer. It was noted that washing hands with soap and water was the best way of keepings the hands clean. However, most young people do not practice hand washing as a result of unavailability of hand washing facilities (water, soaps etc).

The study found out that most homes with toilet facilities do not have set ups facilities for hand washing which makes it difficult for young people to practice hand washing frequently. It was revealed that the initiative has helped minimized the rate at which people get typhoid, fever and infections in the district.

Stakeholders (teachers, parents, health workers, community leaders and NGO's) in the hand washing initiative have played vital role in promoting hand washing in most communities in the district. The stakeholders provide education, sensitization and facilities in promoting effective hand washing initiatives. Non- availability of hand washing equipment and product such as veronica bucket, bucket, bowls, soaps, tanks, water, etc specifically in schools and health facilities were identified as a great challenge that prevents young people from practicing hand washing.

\subsection{Policy Implementation and Recommendations}

The recommendations made in this chapter are intended to capture the attention of young people, parents, teachers, NGOs, health workers, community leaders and the media involved in the support of hand washing among young people, policy makers specifically Ministry of Education, Ministry of Heath, Gender Ministry and research student in the field of hand washing promotion and the health field in general.

The following recommendations are made to ensure effective Hand Washing Initiatives;

1. Consistent education and sensitization on the modes and ways microbes are spread and how effective proper hand washing could address the spread of infections like flu, cold, novel-corona virus, hepatitis A, viral meningitis.

2. Young people also need to be informed on correct method of hand washing that is washing and drying between the fingers since it is essential for getting rid of moist areas where microbes can hide and keeping the hands clean.

3. Soaps and other hand washing materials need to be made readily available in schools, health facilities and at home so that people can practice hand washing effectively.

4. Stakeholders in the hand washing initiative must step up their game and support with hand washing facilities / logistics in schools, health facilities and other public places.

5. There should be extensive education on proper hand washing in the district.

6. The media should be engaged more in promoting and educating the general public on hand washing and the advert effect of not practicing hand washing.

7. The celebration of the Global Hand washing day must be intensified and made compulsory in schools and health facility to help promote consistency and correct hand washing.

8. Young people should further be involved in the yearly Global hand washing day activities to give them the chance to practice hand washing and to take part in the awareness creation.

9. Attention should be given to the formation of clubs with the sole aim of promoting proper hand hygiene, foster knowledge sharing and best practices among young ones.

\section{References}

Adams, Anne and Cox, Anna L. (2008). Questionnaires, in-depth interviews and focus groups. In: Cairns, Paul and Cox, Anna L. eds. Research Methods for Human Computer Interaction. Cambridge, UK: Cambridge University Press, pp. 17-34.

Acocella, I. (2012). The focus groups in social research: advantages and disadvantages. Quality \& Quantity. 46 (4), 1125-1136.

Aiello and Levy (2007). Consumer Antibacterial Soaps: Effective or Just Risky? https://www.ncbi.nlm.nih.gov/pubmed/17683018

Asbury, J.-E. (1995). Overview of Focus Group Research. Qualitative Health Research. 5 (4), 414-420. 
Berg, (1988). Risk Factors for Infection in the Elderly. Institute of Medicine (US) Division of Health Promotion and Disease Prevention; Washington (DC): National Academies Press (US)

Boshell, P. (2017). The Importance of Hand Hygiene at Home and School. Retrieved from http://info.debgroup.com/blog/hand-hygiene-at-home-and-school

Bolt, E., K. Shordt and I. Krukkert, (2006). School sanitation and hygiene education results from the assessment of a 6-country pilot project delft. International Water and Sanitation Centre, Netherlands.

Boycc J., \& Pittett, D. (2013). Guideline for hand hygiene in health-care settings. Morbidity and Mortality Weekly Report 5 (RR16), 1-44.

Boyce, C. and Neale, P. (2006) Conducting In-Depth Interview: A Guide for Designing and Conducting InDepth Interviews for Evaluation Input. Pathfinder International Tool Series, Monitoring and Evaluation-2. http://www.pathfind.org/site/DocServer/m_e_tool_series_indepth_interviews.pdf?docID=6301

Cairncross S, Valdmanis V. (2006). Water Supply, Sanitation, and Hygiene Promotion.

Cairncross S (1997) More water: better health. People and the Planet 6, 3. PubMed Google Scholar.

Cairncross S, Blumenthal U, Kolsky P, Moraes L, Tayeh A (1997) The public and domestic domains in the transmission of disease. Tropical Medicine and International Health 1, 2734.

Wiley Online Library CAS PubMed Web of Science ${ }^{\circledR G o o g l e ~ S c h o l a r . ~}$

Cavana, R. et al. (2001). Applied Business Research: Qualitative and Quantitative Methods (3rd ed.). Australia: John Wiley \& Sons.

Centre for Disease Control and Prevention (CDC). (2017). Clean Hands Count for Safe Healthcare. Retrieved from https://www.cdc.gov/features/handhygiene/index.html

Centre for Disease Control and Prevention (CDC). (2017). When \& amp; How to Wash Your Hands Handwashing. https://doi.org/10.1177/146642406408400650.

Centre for Disease Control and Prevention (CDC). (2015). Handwashing in Community Settings. https://www.cdc.gov/handwashing/when-how-handwashing.html

Centre for Disease Control and Prevention CDC (2015). When and how to wash your hands. Retrieved August 19, 2016 from http://www.cdc.gov/handwashing/when-how-handwashing.html

Christian Council of Ghana Annual Report (2017). 2017 Annual Report. http://www.christiancouncilofghana.org/

Clarke, V. and Braun, V. (2013) Teaching thematic analysis: Overcoming challenges and developing strategies for effective learning. The Psychologist, 26 (2). pp. 120-123. ISSN 0952-8229

Ciobanu, N., Dodos, J., \&Adamonyte, D. (2016). Survey on Hygiene Knowledge, Attitude and Practice. EEHYC Wash in School survey report. P. 10.

Curtis V, Cairncross S, (2016) "Effect of Washing Hands with Soap on Diarrhoea Risk in the Community. Handwashing Research Summary. Periodic Overview of Handwashing Literature. Health in your hands, 6.

Fanteakwa District Assembly Annual Report (2017). 2017 Annual Progress Report.

Global Handwashing Organization. (2017). Announcing the 2017 Global Handwashing Day Theme: "Our Hands, Our Future". Available at: https://globalhandwashing.org/announcing-the-2017-globalhandwashing-day-theme-our-hands-our-future/

Lopez-Quintero, C., P. Freeman and Y. Neumark, (2009). Hand washing among school children in Bogata, Colombia. Am. J. Public Health, 99(1): 94-101

Luby SP, et al. Effect of handwashing on child health: A randomized controlled trial. Lancet, 2015; 366(9481): 225-33.

Luby SP, et al. (2017). Incidences and Costs of Illness for Diarrhea and Acute Respiratory Infections for Children $<5$ Years of Age in Rural Bangladesh. Available at: https://www.ncbi.nlm.nih.gov/pubmed/28167594

Lusk-Stover O. (2016). Globally, periods are causing girls to be absent from school. Education for Global Development. The World Bank.

Palys, T. (2008). Purposive sampling. The Sage Encyclopedia of Qualitative Research Methods. Lisa M. Given. London, SAGE Publications, Inc. 1\&2. http://dx.doi.org/10.4135/9781412963909.n349

Prater, K. (2016). Poor hand hygiene by college students linked to more occurrences of infectious diseases, medical visits, and absence from classes. American Journal of Infection Control. Available at: http://www.ajicjournal.org/article/S0196-6553(15)00929-3/abstract

Pickering AJ, et al. (2013). Access to Waterless Hand Sanitizer Improves Student Hand Hygiene Behavior in Primary Schools in Nairobi, Kenya. Am J Trop Med Hyg, 2013; 89(3): 411-18.

Rabie T. \& V. Curtis (2006). Handwashing and respiratory infections; a quantitative systematic review. Journal of Tropical Medicine and International Health

Rabie. T, (2003). Handwashing and risk of respiratory infections: a quantitative systematic review. Department of Infectious and Tropical Diseases, The Hygiene Centre, London School of Hygiene and Tropical Medicine, London, UK, volume 11 no 3 pp 258-267 
Scott, E. (2013). Community-based infections and the potential role of common touch surfaces as vectors for the transmission of infectious agents in home and community settings. American Journal of Infection Control. Retrieved August 12, 2016 from http://www.ajicjournal.org/article/S0196-6553(13)00938-3/references

School Health Education Programme (SHEP), 2008. SHEP Report. January, Ministry of Education, Ghana.

Smithson, J. (2008). Focus groups. In Denzin, N. and Lincoln, Y. (eds.) Handbook of Qualitative Research. 2nd Ed. Thousand Oaks, CA: Sage Publications.

Smith-Asante, E. (2012). Handwashing most critical in Ghana because of what citizens eat... Available at: https://www.newsghana.com.gh/handwashing-most-critical-in-ghana-because-of-what-citizens-eat/

Stewart, D.W. \& Shamdasani, P.N. (1990). Focus Group. Theory and Practice. Newbury Park: Sage.

Stake, R. (1995). The art of case study research. Sage Publications, Thousand Oaks, (pp. 49-68).

UNICEF (2017). Levels \& Trends in Child Mortality: Report 2017.

UNICEF (2015). Water, Sanitation and Hygiene Annual Report 2015. https://news.un.org/en/story/2015/10/512662-handwashing-day-unicef-warns-inadequate-hygieneendangers-key-development-goal

UNICEF (2014). Water, Sanitation and Hygiene Annual Report 2014. https://www.unicef.org/wash/files/WASH_Annual_Report_Final_7_2_Low_Res.pdf

UNICEF (2013). Improving Child Nutrition: The achievable imperative for global progress.
UNICEF (2012). Water, Sanitation and Hygiene (WASH) in Schools. https://www.unicef.org/publications/files/CFS_WASH_E_web.pdf

UNICEF (2010). Water, Sanitation and Hygiene (WASH) in Schools. https://www.unicef.org/publications/files/CFS_WASH_E_web.pdf

Verplanken, B., \& Wood, W. (2006). Interventions to break and create consumer habits. Journal of Public Policy and Marketing, 25, 90-103.

Vindigni, Riley, and Jhung (2011). Systematic review: handwashing behaviour in low- to middle-income countries: outcome measures and behaviour maintenance. Available at: https://www.ncbi.nlm.nih.gov/pubmed/21226794

Vindigni, S.M., P.L. Riley, and M. Jhung, (2011). Systematic review: Handwashing behavior in low- to middleincome countries: outcome measures and behavior maintenance. Tropical Medicine \& International Health, 2011. 16(4): p. 466-477.

World Health Organization (2013). Health care-associated infections: Fact sheet.

World Health Organization (2017.). Evidence of hand hygiene to reduce transmission and infections by multidrug resistant organisms in health-care settings.

WHO. (2009) WHO Guidelines on Hand Hygiene in Health Care: First Global Patient Safety Challenge. Clean $\begin{array}{lllll}\text { Care Is Safer } & \text { Care. }\end{array}$ http://whqlibdoc.who.int/publications/2009/9789241597906_eng.pdf.

WHO (2008). Safer water, better health: Costs, benefits and sustainability of interventions to protect and promote health.

World Health Organization. (2008). WHO Guidelines on Hand Hygiene in Health Care: WHO Press, 20 Avenue, 1211 Geneva 27, Switzerland.

Yin Robert K. (2003). Case study research design and methods. Sage Publications, Thousand Oaks, $3^{\text {rd }}$ ed. pp. 240

Zikmund and Newman, (2007). Business Research Methods, Zikmund 8th_edition.pdf https://www.academia.edu/33978482/Business_Research_Method

Abdul Hamid, A.S. (1996). The civil service: Towards a new era. Kuala Lumpur: Pelanduk Publications. 